\title{
Ofsted and Children's Services: What factors are associated with better inspection results?
}

\section{Abstract}

'Failing' an Ofsted inspection has severe consequences for a local authority. Senior managers may lose their jobs and the workforce as a whole can be destabilised. In extreme cases, central government can decide the authority is no longer capable of running children's services. On the other hand, receiving positive Ofsted judgements often brings with it a national reputation for excellence. This study reports the findings of an analysis of key performance indicators, expenditure and deprivation in relation to Ofsted inspections for 87 local authorities in England undertaken between 2014 and 2016. Our aim was to examine the association between these factors and Ofsted judgements. Our findings suggest that for most of the factors we considered, there is no clear pattern of better or worse performance between local authorities with different Ofsted ratings. However, 'good and outstanding' authorities tend to outperform other authorities in relation to some procedural variables. By itself, the level of local authority deprivation was most clearly associated with the Ofsted rating and expenditure was associated with the authority's deprivation level, but not their Ofsted judgement. Comparisons are made with the Department of Education's concept of 'value added' education in relation to schools.

Key words: social work, children's services, inspection, OFSTED, deprivation

\section{$\underline{\text { Introduction }}$}

The Office for Standards in Education, Children's Services and Skills (Ofsted) is responsible for the inspection of children's services in England. The aim of these inspections is to "raise standards and improve lives" (Ofsted, 2014, p. 5). Yet, in the past Ofsted have been criticised for focusing too much on compliance with policies and procedures and not enough on "the experiences of children, young people and their families" (Munro, 2011, p. 7). In response to these criticisms, Ofsted revised their inspection framework to focus more on the quality of practice and outcomes for children and less on compliance. Under this new framework, Ofsted inspects children's services across three areas - Child Protection, Looked After Children and Leadership - and provides an overall judgement of 'inadequate', 'requires improvement', 'good' or 'outstanding'. Under this new framework, it has proven more 
difficult for local authorities to achieve a grade of 'good' or 'outstanding' than before. In Ofsted's 2016 annual social care report, the most recent published within the time-frame considered for this article (2014 - 2016), of the 87 authorities inspected, just $2 \%$ were graded outstanding, $27 \%$ good, $56 \%$ requires improvement and $27.5 \%$ inadequate. This compares with $9 \%$ outstanding, $69 \%$ good and $22 \%$ adequate in $2007 / 8$, during which year no authorities were rated inadequate (Impower, 2015).

This may suggest 'the bar has been raised' for children's services and yet it has also been argued that these judgements do not take sufficient account of local deprivation and spending levels (Rowlands, 2010; Bywaters et al., 2014a; 2014b; Jones, 2015a). In 2015, the government announced that when children's services are judged to be 'inadequate', they could be subject to mandatory intervention by the Department for Education (HM Government, 2015). In some places, such as Doncaster and Slough, responsibility for the provision of children's services has been removed from the local authority. Even in less extreme circumstances, it remains the case that the impact of a negative Ofsted judgement can still be problematic - "confidence...is lost, thresholds become very low...the workforce implodes and becomes unstable...there is a heavy dependence on agency workers...workloads increase...backlogs of assessment build up, cases are unallocated and corners are cut" (Jones, 2015b).

Despite the significant influence that Ofsted has (Tilbury, 2004), compared with the education sector, we know comparatively little about their inspections of children's services. There have been numerous studies of Ofsted's school inspections, including whether they improve the quality of provision (Rosenthanl, 2004), whether they make a difference to GCSE results (Shaw et al, 2003), how schools behave before and after an inspection (Ouston et al, 1997) and whether Ofsted's judgements are reliable (Campbell and Husbands, 2000). In relation to children's services, far less has been published. Notable exceptions include a Local Government Association report into whether Ofsted inspections help improve children's services (Impower, 2015). This report found that when a department is judged to be 'inadequate' or 'in need of improvement', they tend to suffer "an accelerated decline" (2015, p. 3).

How do Ofsted inspect local authorities? 
We do, however, know what methods Ofsted use when inspecting children's services, because their inspection handbook is a public document (Ofsted, 2017a). It describes a "combination of case-tracking, case sampling, observations of practice and interviews" (p. 23). The latter may be conducted with social workers, children and young people, parents and carers, foster carers and adopters and senior staff within the authority. Inspectors may also spend time "shadowing staff in their day-to-day work" and "observing practice in multiagency/single agency meetings" (р. 24). This suggests that Ofsted take a holistic approach, focused on the quality of practice and outcomes for children and families. They do so by gathering data from a variety of sources, much more broadly than performance indicators, then seeking to "triangulate [the] evidence" (p. 32 and p. 35). This approach has been both commended and critiqued by Munro (2014) who said, "the new framework is looking at the right aspects of work" (p. 1) but that "the complicated causal links between professional practice and outcomes make it difficult to make judgements about causality" (p. 2). In other words, although the inspection framework sets out what Ofsted inspectors do (they read case files and other reports, interview key stakeholders and observe social workers and managers in the office and in meetings), it is not clear how they use this data to form a judgement about overall and service-level quality.

\section{What factors are associated with different Ofsted judgements?}

The question of what factors are most strongly associated with Ofsted's judgments is critical. To date, we are aware of only one other published study that explored this question in relation to Ofsted's new inspection framework. La Valle et al. (2017, p. 21) looked at 11 performance variables (mostly related to children in care) and found no significant associations between improved performance and better Ofsted judgements. Indeed, two of the best performing authorities - Lambeth and Sandwell - were judged by Ofsted to be 'inadequate' while one of the worst performing authorities - East Sussex - was judged to be 'good'. Similarly, in relation to Ofsted's previous inspection framework, Hood et al (2016) examined all 152 local authorities in England and found three variables predicted an 'inadequate' judgement - fewer timely assessments, higher re-referral rates and higher proportions of agency workers.

There is a clear need for more research regarding the role of Ofsted in relation to children's services. Such research would help us understand more clearly how Ofsted form 
their judgements and how inspection activity could be improved. With this paper, we aim to contribute to this debate by exploring which of the variables we included, if any, were associated with Ofsted's judgements.

\section{Aims and objectives}

In this study, we sought to address the following two questions - (1) What is the association between selected local authority performance variables, expenditure, deprivation and Ofsted judgements? And (2) Can they explain differences in obtained Ofsted ratings?

\section{Method}

We explored the relationship between a selection of key variables and Ofsted judgements for 87 English local authorities inspected between 2014 and 2016 (at the time of data collection, this represented every authority inspected under that framework). Each of the key variables relates to one of three areas - finance and spending, levels of deprivation and performance. All the data are publically available. (Spending, finance and key performance data from the Department for Education; deprivation data from the Department for Communities and Local Government and inspection data from Ofsted.)

\section{Measures of Ofsted's judgements}

Ofsted inspection data for each local authority were retrieved from Ofsted's website. We started by considering the association between the overall Ofsted judgement and each of the sub-category judgements (for Child Protection, Looked After Children and Leadership). As the correlations were so high, for the rest of our analysis we used only the overall Ofsted judgement for each authority (Table 1).

\section{$<$ Insert Table 1 about here $>$}

We placed each authority into a category - low, medium or high - depending on their overall judgement. Local authorities with an 'inadequate' judgement were placed into the low category ( $n=22$ ). Local authorities 'in need of improvement' were placed into the medium category $(n=44)$. As there were relatively few high-performing authorities at the time of our study, those judged 'good' or 'outstanding' were placed into the high category $(n=21)$. 


\section{Measures of spending}

Obtaining an accurate estimate of local authority spending is difficult, not least because local authorities report spending in different ways (Bywaters et al., 2015; Bywaters, Webb and Sparks, 2017). For this study, we used local authority budget returns to obtain a total spending figure for children's services in the financial year of their most recent Ofsted inspection. These figures were adjusted for inflation to 2015/16 levels using the retail price index. We divided this figure by the local child population at the time of the Ofsted inspection (using Ofsted's own figures), resulting in a 'spending per child' estimate for each authority.

There are clear limitations to this approach, not least because not all authorities report spending data in the same way and because all authorities target their spending more heavily on some children than others. In addition, although it is relatively easy to know how many 'children in need' and 'children in care' there are in each authority, the breadth of local authority spending on children and families is far wider than this, including social work assessments (many of which may be undertaken with children subsequently found not to be formally 'in need'), early years support, children's centres and Sure Start, youth services and family support services. Obtaining reliable usage figures for each of these services in each authority is practically very difficult.

Thus, we acknowledge there are clear limitations to our approach and that a nominal 'spending per child' figure may not represent actual spending patterns (although it is also worth nothing similar figures have been used by other researchers in this field; Bywaters, Webb and Sparks, 2017).

\section{Measures of Deprivation}

Using the English Indices of Deprivation 2015, we ranked each local authority from least deprived (Woking) to most deprived (Manchester). Although ranking at the level of local authority obscures within-authority variation, as with spending data, this approach provides at least an indication of the relative position of each authority. We removed those authorities not included in our sample and re-ranked the remaining authorities from one to eighty-seven. 
Finally, we obtained key variables in relation to child protection (CP) and looked after children services (LAC) for each local authority for the year immediately prior their most recent Ofsted inspection (Table 2). These data were obtained from the Department for Education (DfE) website. Some of these indicators relate to procedural outputs (e.g. the proportion of assessments completed outside of statutory timescales) and some to good practice or even outcomes (e.g. the proportion of children in care who did not achieve 'good' GCSE results). We chose these indicators based on our own judgement about their likely significance, and because many of them are routinely discussed and cited in the wider literature (e.g. Bilson and Martin, 2016). This means there are inevitably other indicators that we did not include (e.g. the number of special guardianship orders).

<Insert Table 2 about here>

\section{Strengths and Limitations}

The key limitations of our study are (1) the lack of reliable local authority spending data, (2) the use of authority-level deprivation data and (3) missing data from some local authorities.

First, the spending data we used is likely not entirely accurate. Different local authorities report their spending in different ways and while we have tried to take account of those differences when calculating 'spend per child' figures, we inevitably had to make some subjective decisions. It is possible that someone else looking at the same data might arrive at a different figure for at least some of the authorities. However, until there exists more accurate and consistent data, the approach we used is at least reasonably indicative. It is also a limitation that our 'spend per child' figures relate to the overall child population in each authority and not specifically to children referred to social services. Having said this, councils do spend money on the whole child population for example, via community projects, and some of this investment is intended to prevent families from needing more specialist services.

Second, our deprivation data relates to entire local authority areas. This approach masks within-authority variation (Bywaters et al., 2014a). As with the spending data, this means a degree of caution is warranted when interpreting our findings. 
Third, not all local authorities provided a complete set of data to the DfE regarding the key variables we used. For example, only 44 of the 87 authorities provided data on the number of children in care with 5 or more 'good' GCSEs.

Strengths of the study include the relatively large number of local authority variables we considered (fifteen in total) and the combination of performance, practice or outcome, spending and deprivation data. Finally, the 87 authorities included in the sample represent more than 50 per cent of the total number of authorities in England and thus, the patterns of association we report are likely to represent what happens in the remaining authorities as well.

\section{Findings}

Sample

Table 3 shows the number and percentage of authorities in each of our Ofsted categories ('inadequate', 'in need of improvement' and 'good and outstanding') compared to high, medium and low levels of deprivation.

<Insert Table 3 about here>

\section{Associations between Ofsted judgements and key variables}

Spearman's rho non-parametric correlational analyses were performed to establish the pattern of relationships between Ofsted judgements and the key CP and CLA variables. Significant correlations were found between Ofsted judgements and levels of deprivation (Spearman's rho=-.245, p=.022), Ofsted judgements and assessments overdue (Spearman's rho=-.224, $p=.043)$, and Ofsted judgements and children in care with 'missing episodes' (Spearman's rho=.519, $\mathrm{p}<.001$ ). Table 4 depicts the statistically significant associations.

<Insert Table 4 about here>

\section{Comparison of means between Ofsted categories}

We calculated the overall mean between our three Ofsted categories for a selection of key variables. We calculated the mean per Ofsted category for a group of 'practice' variables repeat referrals, Child in Need (CIN) and CP plans lasting longer than two years, repeat CP 
plans (where the same child is subject of a CP plan more than once), children in care persistently absent from school, children in care with a missing episode and children in care without 5 'good' GCSEs. (In England, Child in Need and Child Protection plans are used to coordinate support for children and their families. The key difference between them is that Child in Need plans are used when the child is 'in need' of additional support and are legally voluntary (they cannot be implemented without parental consent), whereas Child Protection plans are used when the child is at risk of significant harm and can be implemented without parental consent.) For these variables, a lower number indicates better performance (Table 5 and Table 6). To take one example, for the group of 'inadequate' authorities we considered, they had an average of $23.2 \%$ repeat referrals. This compares with figures of $21.7 \%$ in 'in need of improvement' authorities and $21.2 \%$ in 'good and outstanding' authorities. (The figures for standard deviation give an indication of the range of performance in each of these groups). Thus, in relation to this performance indicator, there is little difference, on average, between the three groups.

$<$ Insert Tables 5 and 6 about here $>$

Second, we calculated the mean per category for a group of procedural variables Initial (ICPC) and Review Child Protection Conferences overdue, CP visits overdue and Assessments overdue. For these variables, a lower number indicates better performance (Table 7).

\section{$<$ Insert Table 7 about here $>$}

Local authorities in the 'good and outstanding' category perform better than the overall mean for seven of these variables - ICPCs overdue, CP review conferences overdue, CP visits overdue, assessments overdue, $\mathrm{CP}$ plans lasting more than two years, repeat referrals and children in care persistently absent from education. The same authorities underperform against the overall mean in a further four variables - CIN plans lasting longer than two years, repeat $\mathrm{CP}$ plans, children in care with a missing episode from care and children in care without 5 'good' GCSEs. 
Local authorities in the 'inadequate' and 'in need of improvement' sometimes outperform and sometimes underperform relative to the overall mean. Sometimes, these authorities outperform those in the 'good and outstanding' category. For example, for local authorities 'in need of improvement', the mean for children in care without 5 'good' GCSEs is 77.5\%, compared with $83.3 \%$ for the 'good and outstanding' category (a lower number for indicates better performance). Similarly, for 'inadequate' authorities, the mean for repeat CP plans is $16 \%$, compared to $17.7 \%$ for 'good and outstanding' authorities (ditto).

\section{Ofsted categories and spending}

We calculated the overall mean 'spend per child' for our three different Ofsted categories. The figure for all 87 authorities was $f 854.60$. Analysis of variance between each of our Ofsted categories did not produce any statistically significant differences on expenditure ( $p>.05)$. When levels of deprivation are taken into account, an analysis of variance yielded significant differences between local authorities in terms of spend per child, for the 'inadequate category' $(F(2,21)=4.83, p=.02)$; for the 'in need of improvement' category $(F(2,43)=13.26, p=.000)$; and for the 'good and outstanding' category, $(F(2,20)=9.42, p=.002)$. Post hoc Tukey tests showed that spend per child was significantly different between the low and high deprivation groups $(p<.05)$; whereas the medium deprivation group was not significantly different from the other two groups. Considered in this way, spend per child in relation to level of deprivation is significantly different for the 'inadequate' Ofsted category (Table 8).

$<$ Insert Table 8 about here $>$

\section{Associations with Ofsted category ratings}

To explore which variables were associated with Ofsted judgements, a series of multinomial logistic regression analyses were performed for the reference category 'inadequate' and for the reference category 'in need of improvement'. (Ordinal regression analyses were first performed on the data but because the assumptions were violated, multinomial logistic regressions were then performed.) The following variables were significantly associated with Ofsted judgements: 
- Deprivation level - the deprivation rank of the local authority was a significant predictor for membership of the 'good and outstanding' category, $(\beta=-1.06$, Wald $\left.\chi^{2}(1)=6.06, p=.014\right)$. Deprivation rank was also found to be significantly associated with a 'good and outstanding' Ofsted judgement after accounting for spend per child, $\left(\beta=-1.52\right.$, Wald $\left.\chi^{2}(1)=7.87, p=.005\right)$. However, spend per child by itself was not found to be significantly associated with Ofsted judgements ( $p>05)$.

- Assessments Overdue - the proportion of assessments overdue was a significant predictor for membership of the 'good and outstanding' category, ( $\beta=-.055$, Wald $\left.\chi^{2}(1)=4.36, p=.037\right)$.

- Missing episodes from care - The proportion of children in care with a 'missing episode' was also a significant predictor for membership of the 'good and outstanding' category, $\left(\beta=.583\right.$, Wald $\left.\chi^{2}(1)=9.44, p=.002\right)$.

It is important here to be clear about the meaning of the word 'predictor' in this context. We did not undertake a longitudinal study, so we are not here talking about predictive in the sense of future performance. Rather, knowing the deprivation level of the local authorities included in this study allows us to predict their membership of the different Ofsted categories we used.

\section{Summary of findings}

- Of the 87 local authorities in our sample, the majority were found to be 'inadequate' or 'in need of improvement' $(n=66)$.

- Ofsted's overall judgements and sub-category judgments (for Child Protection, Looked After Children and Leadership) are highly correlated.

- For a selection of the key variables we looked at, including percentage of repeat referrals, $\mathrm{CIN}$ and $\mathrm{CP}$ plans lasting more than two years, repeat $\mathrm{CP}$ plans, children in care persistently absent from education, children in care with five 'good' GCSES, CP conferences overdue, CP visits overdue and assessments overdue, we found no clear pattern of performance between the different Ofsted categories.

- On several of these measures - repeat referrals, CIN plans lasting more than two years, repeat $\mathrm{CP}$ plans, children in care with missing episodes and children in care without 
'good' GCSE results - authorities in the 'inadequate' and 'in need of improvement' categories report comparable or better results than authorities in the 'good and outstanding' category.

- Different levels of performance in relation to the CP 'practice' variables (repeat referral rate, repeat child protection plans, length of CIN or CP plans) was not associated with the Ofsted rating of the local authority.

- 'Good and outstanding' authorities outperform other authorities in relation to some procedural variables - child protection conferences overdue, $\mathrm{CP}$ visits overdue and assessments overdue.

- Within each Ofsted category, high deprivation authorities with 'good and outstanding' ratings spend significantly more than other high deprivation authorities.

- Spend per child alone was not associated with whether a local authority will appear in the 'good and outstanding', 'in need of improvement' or 'inadequate' category.

- Deprivation is the strongest single predictor of whether a local authority will appear in the 'good and outstanding', 'in need of improvement' or 'inadequate' category.

\section{Discussion}

We examined the relationship between a range of key local authority variables, levels of spending, levels of deprivation and Ofsted judgements. It would be reasonable to hypothesise that authorities with better Ofsted judgements would consistently outperform authorities with worse Ofsted judgements, at least for some of these variables if not for all of them. For example, one might expect that 'good and outstanding' authorities have lower rates of re-referral and repeat $\mathrm{CP}$ plans than other authorities - but in the sample we considered, they did not. However, 'good and outstanding' authorities did outperform other authorities in terms of procedural compliance, for example, having fewer overdue assessments, $\mathrm{CP}$ visits and $\mathrm{CP}$ conferences.

It is important to note that Ofsted do not claim to base their judgements on the variables we have considered in this paper - and there is no suggestion by us (or by anyone else) that they should. A reliance on easily-measured performance indicators has been roundly criticized within the profession (Wastell et al, 2010) and our findings indicate that Ofsted judgements do not, in any case, correlate clearly with key performance data. However, this finding is itself confusing. If Ofsted were solely focused on performance, authorities who 
held more meetings on time might consistently achieve better judgements - and we did not find this to be the case. But on the other hand, if Ofsted were solely focused on outcomes, perhaps those authorities in which children in care achieved better school performance would consistently achieve better judgements (at least in relation to their looked after children services) - but we did not find this to be the case either.

In relation to spending, one might hypothesise that 'good and outstanding' authorities simply outspend other authorities. In fact, from an initial consideration of 'face validity', our figures suggest that higher performing authorities ('good and outstanding') actually spend less money per child than underperforming authorities ('in need of improvement' or 'inadequate'). This finding echoes an earlier judgement by the National Audit Office (2016) that there is "no correlation between local authorities' spending on children in need and the quantity and quality of their services" (p. 26). However, when we compared mean spend per child for levels of deprivation within each Ofsted category, it became clear that 'good and outstanding' authorities do spend considerably more when they have higher levels of deprivation and much less when they have lower levels of deprivation than authorities in the 'inadequate' or the 'in need of improvement' categories.

Of all the variables we considered, we found only one that by itself predicted membership of the 'good and outstanding' category. The more deprived the authority, the more likely it was to be judged 'in need of improvement' or 'inadequate' and the less deprived, the more likely it was to be judged 'good and outstanding'. Although some of the other variables we considered have some individual predictive power, the level of deprivation is the only variable to retain predictive power when combined with other variables. Recently, Ofsted themselves have become aware of this potential relationship, saying in their latest annual report, "We have begun looking at these [data] and we found some correlation between the level of deprivation in the area and overall effectiveness" (2017b, p. 70). This represents an apparent shift from the previous year's report, in which it was stated that "inadequacy is not a function of size, deprivation or funding (Ofsted 2016, p. 5, emphasis added). Ofsted say they will publish the results of their own investigations regarding the relationship between performance and deprivation in early 2018.

\section{Another approach?}


When evaluating the performance of secondary schools, the DfE take into account that different schools have different pupil intakes. They do so by calculating the 'value added' by each school, assessing the progress made by pupils from key stage two (Year 6 ) to key stage four (Year 11). This approach recognises that although all pupils can make progress, some pupils experience more disadvantage. Thus, achieving good outcomes is more difficult for some schools than for others. It also recognises that such difficulties are not directly related to the quality of teaching, important though this is. For example, pupils in school A achieve better GCSE results at key stage four than pupils in school B. But pupils in school B make greater progress between key stage two and key stage four than pupils in school A. As a result, school B will have a higher 'value added' score than school A. According to the DfE, this 'value added' measure is the best indication of a school's overall effectiveness.

However, measuring the performance of children's services is much more difficult than measuring the performance of schools (Forrester, 2017, Malley and Fernandez, 2010). Pupils can be asked to take standardized exams, not only at GCSE and A-level but theoretically at any point in their school career. The results of these tests can be compared at local, regional, national and even international level. Evaluating the performance of children's services is much more complicated. When a child comes into care, this might represent the best possible outcome for a child who would otherwise experience significant harm at home with their family. Or it might represent a failure on the part of children's services - and on the part of society as a whole - to adequately support the child's family. This complexity may explain why for so long the sector has relied on measuring things that are easy to count, such as the number of assessments completed on time, rather than the things that really matter but which are harder to quantify, such as the quality of those assessments.

\section{Conclusion}

Much of the publicly available data provided by local authorities to the DfE relates not to the quality of practice or outcomes for children but to output. In the past, Ofsted inspections have been criticised for being overly concerned with compliance and insufficiently focused on the quality of practice and outcomes. In the time since we completed our analysis for this paper, Ofsted (2017a) published a revised inspection framework and explicitly identified the need to strike a balance between a rigorous and objective inspection and the need to help authorities improve rather than risk hindering their progress (Schooling, 2017). It 
would no doubt make for an interesting future analysis to consider a new set of inspection judgements and how they relate to an even broader set of performance indicators.

Understanding whether (and how) children's services are of sufficient quality is a key question for children, families, professionals and policy-makers. Yet it is important not to ignore the importance, significance and influence of wider social factors too. As Bywaters et al $(2015,2017)$ have found, there is a strong relationship between deprivation and intervention rates and large inequities between ethnic categories. It is almost inconceivable that this relationship would not also be apparent within the pattern of Ofsted judgements across the country. No-one is suggesting we should lower our aspirations for children's services, or that high deprivation should offer an easy excuse for poor practice. Yet, it is undoubtedly the case that the wellbeing and welfare of children and their families does not result simply from the quality of help provided by children's services. Put simply, providing effective help for children and families is harder when levels of deprivation are high - and a holistic inspection regime should take this into account.

\section{$\underline{\text { References }}$}

Bywater, P., Brady, G., Sparks, T. and Bos, E. (2014a) Inequalities in child welfare intervention rates: the intersection of deprivation and identity. Child and Family Social Work, 21(4), pp. $452-463$.

Bywaters, P., Brady G., Sparks T. and Bos E. (2014b) Child welfare inequalities: New evidence, further questions. Child \& Family Social Work, 21(3), pp. $369-380$.

Bywaters, P., Brady, G., Sparks, T., Bos, E., Bunting, L., Daniel, B., Featherstone, B., Morris, K. and Scourfield, J. (2015). Exploring inequities in child welfare and child protection services: explaining the 'inverse intervention law'. Children and Youth Services Review, 57, pp. 98- 105.

Bywaters, P., Brady, G., Bunting, L., Daniel, B., Featherstone, B., Jones, C., Morris, K., Scourfield, J., Sparks, T. and Webb, C. (2017). Inequalities in English child protection practice under austerity: A universal challenge? Child and Family Social Work, 23(1), pp. $53-61$.

Bywaters, P., Webb, C. and Sparks, T. (2017) Ofsted ratings do reflect local authority deprivation and spending. Available at: http://www.communitycare.co.uk/2017/01/18/ofsted-ratings-reflect-local-authoritydeprivation-spending/ [Accessed February 2017].

Campbell, J. and Husbands, C. (2000) On the Reliability of OFSTED Inspection of Initial Teacher Training: A case study. British Educational Research Journal, 26(1), pp. $39-48$.

Forrester, D. (2017) Outcomes in children's social care. Journal of Children's Services. https://doi.org/10.1108/JCS-08-2017-0036 
HM Government (2015) PM: We will not stand by - failing children's services will be taken over. Available at: https://www.gov.uk/government/news/pm-we-will-not-stand-byfailing-childrens-services-will-be-taken-over [Accessed February 2017].

Hood, R., Grant, R., Jones, R. and Goldacre, A. (2016) A study of performance indicators and Ofsted ratings in English child protection services. Children and Youth Services Review, 67, pp. $50-56$.

Hood, Rick, Goldacre, Allie, Grant, Robert, \& Jones, Ray (2016). Exploring demand and provision in English child protection services. British Journal of Social Work, 46(4): 923-941. Published online 2016, May 13. doi: 10.1093/bjsw/bcw044.

Impower (2015) A Brave New World: Is inspection improving Children's Services? Available at: http://www.impower.co.uk/insights/a-brave-new-world-is-inspection-improvingchildrens-services [Accessed February 2017].

Jones, R. (2015a). The end game: The marketisation and privatisation of children's social work and child protection. Critical Social Policy, 35(4), 447-469.

Jones, R. (2015b) Ofsted doesn't recognise the practice chaos and professional carnage it leaves in its wake. Available at: http://www.communitycare.co.uk/2015/05/07/ofsteddoesnt-recognise-practice-chaos-professional-carnage-leaves-wake/ [Accessed March 2017].

La Valle, I., Holmes, L., Gill, C., Brown, R., Hart, D. and Barnard, M. (2016) Improving Children's Social Care Services. Results of a feasibility study. Available at:

http://www.corc.uk.net/media/1415/201611improving childrens social care service s.pdf [Accessed February 2017].

Malley, J. and Fernandez, J. (2010) Measuring quality in social care services: theory and practice. Annals of public and cooperative economics, 81(4), pp. $559-582$.

Munro, E. (2011) The Munro Review of Child Protection: Final Report. A child-centred system. Available at:

https://www.gov.uk/government/uploads/system/uploads/attachment data/file/175 391/Munro-Review.pdf [Accessed February 2017].

Munro, E. (2014) Review of first eleven Ofsted inspections of services for children in need of help and protection, children looked after and care leavers, and Local Safeguarding Children's Boards. Available at:

https://assets.publishing.service.gov.uk/government/uploads/system/uploads/attach ment data/file/396378/Review by Professor Eileen Munro of the first eleven Ofs ted inspections of children s services and reviews of LSCBs.pdf [Accessed May 2018].

National Audit Office (2016) Children in need of help or protection. Available at: https://www.nao.org.uk/wp-content/uploads/2016/10/Children-in-need-of-helpprotection.pdf [Accessed February 2018].

Ofsted (2014) Raising standards, improving lives: The Office for Standards in Education, Children's Services and Skills (Ofsted) Strategic Plan 2014 to 2016. Available at: https://www.gov.uk/government/uploads/system/uploads/attachment data/file/379 920/Ofsted 20Strategic 20Plan 202014-16.pdf [Accessed February 2017].

Ofsted (2016) Ofsted social care annual report 2016. Available at: https://www.gov.uk/government/publications/ofsted-social-care-annual-report-2016 [Accessed February 2017].

Ofsted (2017a) Framework and evaluation schedule for the inspections of services for children in need of help and protection, children looked after and care leavers. Available at: 
https://www.gov.uk/government/uploads/system/uploads/attachment data/file/662 790/Inspection handbook inspections of services for children in need of help an d protection.pdf [Accessed February 2018].

Ofsted (2017b) The Annual Report of Her Majesty's Chief Inspector of Education, Children's Services and Skills 2016/17. Available at:

https://www.gov.uk/government/uploads/system/uploads/attachment data/file/666 871/Ofsted Annual Report 2016-17 Accessible.pdf [Accessed February 2018].

Ouston, J., Fidler, B. and Earley, P. (1997) What Do Schools Do after OFSTED School Inspections - or before? School Leadership and Management, 17, pp. $95-104$.

Rosenthanl, L. (2004) Do school inspections improve school quality? Ofsted inspections and school examination results in the UK. Economics of Education Review, 23(2), pp, 143 151.

Rowlands, J. (2010) Services are not enough: child well-being in a very unequal society, Journal of Children's Services, vol. 5(3), pp. 80-88.

Schooling, E. (2017) A new inspection system. Available at: https://socialcareinspection.blog.gov.uk/2017/11/29/a-new-inspection-system/ [Accessed May 2018].

Shaw, I., Newton, P., Aitkin, M. and Darnell, R. (2003) Do OSFTED inspections of Secondary Schools Make a Difference to GCSE Results? British Educational Research Journal, 29, pp. $63-75$.

Simmons, A. (2015) Ofsted inspections harm children's services, says report. Available at: http://www.bbc.co.uk/news/education-32496105 [Accessed February 2017].

Tilbury C. (2004) 'The influence of performance measurement on child welfare policy and practice', British Journal of Social Work, 34(2), pp. 225-41.

Wastell, D., White, S., Broadhurst, K., Peckover, S. and Pithouse, A. (2010) Children's services in the iron cage of performance management: street-level burearacy and the spectre of Svejkism. International Journal of Social Welfare, 19(3), pp. 310-320. 